\title{
PREFACE
}

\section{Advances in targeted therapies IV}

\section{F C Breedveld, J R Kalden, J S Smolen}

Ann Rheum Dis 2002;61 (Suppl II):ii

$\mathrm{T}$ he papers brought together in this supplement of the Annals of the Rheumatic Diseases constitute summaries of presentations at the Fourth International Symposium on Advances in Targeted Therapies which was held in April/May 2002. As such, these presentations represent the state of the art on the biology of mechanisms of action and pathophysiology of tumour necrosis factor (TNF) and interleukin (ILl) as well as other important mediators of inflammation. Current knowledge on the means and consequences of blocking TNF, ILl, or other molecules is presented as well.

We are grateful to Drs Crofford, Feldmann, Furst, Klareskog, Lipsky, Maini, Moreland, and Weinblatt, the members of the advisory board of the symposium, for their invaluable help towards the success of the conference, the fourth of a series of similar events planned for the future. We particularly wish to thank all speakers for their excellent presentations, most of which are summarised here in writing, and all participants who have actively contributed to the discussions. Finally, we also wish to thank the sponsors* of this university driven event who have provided unrestricted educational grants that enabled us to invite the leading scientists in the field. Moreover, a rheumatological audience and the readers of this supplement have been able to obtain back to back information on the efficacy and safety of TNF $\alpha$ and ILl blocking agents from representatives of the major companies involved, with open discussion of issues arising about each agent when looked at individually and compared with others. It is also thankfully acknowledged that representatives of the FDA, EMEA and NICE actively participated in this symposium. Finally, based on the presentations and as a consequence of intensive discussions, a revised consensus statement on the application of TNF and ILl blocking agents in rheumatoid arthritis was formulated. We have to thank particularly Dr Furst for his guidance in this respect.

We hope that the readers of this supplement will enjoy the contributions as much as the participants seemed to enjoy the meeting.

* The conference was organised under the sole responsibility of the departments of the Universities of Erlangen, Leiden, and Vienna in collaboration with an advisory board consisting of the above-mentioned colleagues from departments of rheumatology of several American and European Universities. The following companies provided unrestricted educational grants for the organisation of this conference: Abbott Immunology, Amgen (Europe AG), Centocor, Immunex, Pharmacia, Schering-Plough, and Wyeth Ayerst. The pharmaceutical industry had no part in the decisions about the specific programme and, with the exception of few observers, participants were selected and solely invited by the organising committee. Several members of the advisory board and the members of the organising committee have obtained experience in the use of TNF blocking compounds in the course of their participation in clinical studies on these agents (for which the costs were defrayed by industry). 